\title{
INFO-U FAXBACK: Delivering Consumer Information through Fax-on-demand Technology
}

David E. Whiting ${ }^{1}$

Summary. Through fax-on-demand technology, residents access selected extension service print information 24 hours a day, 7 days a week via touch tone phone. System hardware and software needs are reviewed.

Additional index words. Fax-on-demand, consumer horticultural information

ax-on-demand technology is an excellent match for extension programs, providing customers immediate access to print information, 24 hours a day, 7 days a week. With the multiplier effect of a totally automated system, large audiences can be reached with reduced staff time compared to answering calls on a one-to-one basis. Fax-on-demand technology can become a significant cost savings to extension programs. Each fax sent by INFO-U FAXBACK saves the $M$ innesota Extension Service (M ES) \$2.50 in postage, printing, and handling costs. Fax-on-demand can be a delivery means for printed materials when funds for printing are limited.

I ndustry figures estimate that currently $7 \%$ of American households have fax capacity, with numbers increasing by $30 \%$ a year. $M$ any have accessibility to fax at their work site. Fax service is available in communities through local businesses. Businesses and agencies can serve as collaborators in an extension fax-on-demand system. For example, a local nursery and garden store can provide fax-on-demand as a customer service. 


"A standard
personal
computer
$(P C)$ for
$\$ 1000$ to
$\$ 2000$ becomes
the base of the
automated
system"

"A standard

computer (PC) for $\$ 1000$ to $\$ 2000$ becomes the base of the system"

\section{MES's INFO-U system}

MES'SINFO-U consumer information servicestarted asan audiotext system processing routine inquiries to extension offices. Callers from the toll-free metro calling area ( $60 \%$ of the state population) call a local phone number. Callers in greater $M$ innesota can use an 800 phone line. Content is reflective of current MES issues. Subject matter areas include 1) yard care and gardening, 2) homeenvironment and maintenance, 3) food safety, nutrition and health, 4) family issues, and 5) small acreage production.

The audio message service continues to grow in use. In 1995, the system processed 50,000 inquires, equal to 300 staff days on the phone. Support staff find that transferring callers into INFO-U Audio is a great alternative when staff members are not available to take calls.

As INFO-U Audio was developed, we quickly realized that many routine inquiries are not suitable for a 1- to 2-minute voice message. The subjects may require a longer message or have technical information that is difficult to transmit over an audio system, where the caller cannot ask questions.

To expand access to more technical information, fax-on-demand software and fax boardswere added to the I N FO -U computer system. M ES fact sheets, bulletins, and materials developed for I N FO -U FAX BA CK were loaded onto the database. A file can beloaded from computer text files or scanned from print copy. Files can be added or updated readily. C urrently the system contains some 300 home horticulture and related titles.

Print information becomes available to the public 24 hours a day, 7 days a week. Receiving a catalog of titles or fact sheet by fax is easy. Voice instructions guide the caller to enter their fax number and select a catalog of titles or a fact sheet. The computer calls the fax number entered and transmits the document requested, making up to fiveattempts if a busy number is reached. A typical M ES fact sheet takes 3 to 5 minutes to print via fax

\section{Technical information: Hardware-software}

MES developed this system from components available in the market. This approach reduced capital outlay and allowed us to customize the program to local use. With the rapid growth in telecommunication technology, there are many suppliers in the field that can provide components or turn-key systems. Basic system components include a personal computer, voice boards, fax boards, phone lines, and the database. Time by computer support staff to install and customize the hardware-software was 100 hours.
A standard personal computer (PC) for $\$ 1000$ to $\$ 2000$ becomes the base of the automated system. Current software works on a 486 DX-2-66 PC with a 500 to 1000 megabit hard drive. Telecommunication hardware and software (voice and fax boards) are added to the PC.

Functions of the voice boards ( hardware and software) include the following:

1) Voice is converted by the voice board (hardware and software) into a digital codethat is stored as data on ahard drive.

2) The voice board recognizes the touchtone frequencies and translates it into action commands.

3) The voice board accesses digital messages stored on the hard drive and converts them to analog messages for playback over the phone.

Cost estimates for voice boards run $\$ 1000$ for a two-line starter kit up to $\$ 1500$ for a four-line starter kit.

Fax boards (hardware and software) access files (stored on the hard drive) and transmit them asfax messages. Cost estimates range from $\$ 900$ for a one-line starter kit, with $\$ 250$ for each additional single line fax board, up to $\$ 2300$ for an industrial scale, four-line board.

The M ES system has expanded to eight incoming lines and four outgoing fax lines. Cost estimatesfor phonelinesinclude1) installation $-\$ 80$ to $150 /$ line, 2) monthly line charge $-\$ 20$ to $\$ 60 /$ line, 3) incoming 800 line costs $-\$ 0.08 /$ minute, and 4) outgoing long-distance costs for fax $-\$ 0.20 /$ minute. The M ES system is housed on campus where phone line costs are only $\$ 20 /$ month compared to $\$ 60 /$ month at the county office.

Additional (optional) computer hardwareincludes an noninterruptible power supply for $\$ 400$ to $\$ 500$, a tape back-up unit for $\$ 300$, and a scanner (to scan fact sheets for fax-on-demand system) for $\$ 800$ to $\$ 1000$.

$\mathrm{H}$ ardware-software costs are only part of the system set-up costs. It takes time to develop the database! Turn-key (hardwaresoftware) systems are available from many suppliers for $\$ 7000$ to $\$ 8000$.

\section{Programming decisions for fax- on-demand}

Some fundamental programming decisions to be made in setting up a fax-ondemand system include a one or two call system, graphic or D OS text data file, and user fees.

\section{One- or two-call system}

The program can be set up to process as a one- or two-call system. MES INFO-U FAXBACK uses a two-call system. 
In a two-call system, 1) the customer calls in from any touch-tonephone and 2) the system computer dials the customer's fax number on an outgoing line and transmits the document. Advantages of this system include 1) that it creates a customer-friendly atmosphere where office staff and volunteers (i.e., $M$ aster $G$ ardeners) can send a document and 2) that the system can hold the fax in queue during heavy use and transmit it as phone lines are available.

In a one-call system, the customers call on their fax lines. The document is transmitted during the call. It has the advantage that cost can be picked up on an incoming 800 circuit or pay-per-call 900 circuit, or any long-distance fees will be picked up by the customer.

\section{Database: DOS text files or graphic files}

Thestandard fax machine sendsagraphics transmission or picture of the original document, including graphs, line drawings, and photographs. When printed, it will be a fax-quality reproduction of the original. The advantage of the graphics format is the retention of the formatting and artwork of the original document. Disadvantages of the graphic format include 1) fax quality is sometimes difficult to read, depending on font and print size; 2 ) quality of photosis poor; and 3 ) size of a graphics file is typically 50 times larger than the D OS text format.

In DOS text format, files are stored and transmitted as D O S text with line breaks. This approach has the advantages that 1 ) the fax is printed with the default font of the fax machine, giving it a large (typically 12-point), easy-to-read font; 2) a typical fact sheet (one page printed front and back) requires only 5000 to 12,000 bits of memory; and 3) pictures, which do not transmit well on fax, are eliminated. Disadvantages of this approach include 1) the elimination of changes in font size (headings), bolding, italics, etc. (headings are converted to all caps and set off by spacing) and 2) graphsand linedrawingsare eliminated.

Based on the readability of the faxed document and photo quality, MES decided to use the DOS text format. We sacrificed graphsand linedrawingsfor readability of the text. In I NFO-U FAX BA CK, weidentify the cut line of pictures, line drawings, and graphs and give the associated text. $O$ ur documents instruct the customer on how to purchase a print copy with artwork.

\section{Free or fee based}

Being a phone access method, the option exists for using 900 pay-per-call phone circuits as a revenue source. MES defined INFO-U FAXBACK as a noncharge service.
The decision was based on the concept that many employers are willing to provide fax access to employees, but few would bewilling to pick up 900 line charges on the company phone bill. The horticulture industry is strongly supportive of INFO-U FAX BACK as a public service. It opposed the service as a revenue source.

\section{Promotion and use}

The success of an audio-fax-on-demand system is keeping it visible to the public through constant promotion. U se directly reflects current promotion. With the MES INFO-U system being county based, local staff have ownership and responsibility for promoting its use.

System hardware-software was purchased by MES. Local counties pay ongoing program costs. To participate in the system, $M$ innesota counties currently pay $\$ 125 /$ year per agent FTE plus local promotional costs. The yearly assessment pays for phone lines, 800 line charges, system-wide promotional support, and system maintenance.

For the fax-on-demand system, MES hastaken the marketing approach of instructing the caller to request a catalog of titles by fax. Promotion is focused on accessibility of print materials.

Some of the successful efforts for promotion includes the media, extension service volunteers (including $M$ aster $G$ ardeners), collaboration with other agencies where we share a common message, collaboration with businesses as a public service, and cross promotion with other extension programs.

\section{Time commitment}

It takes staff time to prepare the files in the database, to review and update information routinely, and to promote system use. As MES developed the INFO-U FAXBACK system, we underestimated the time commitment necessary to set up the database. Time estimates include the following:

1) Reformat existing fact sheets or new materials, which are edited and reviewed for distribution, into DOS text format- 10 to 60 minutes/ fact sheet.

2) U pdate catalog -5 minutes/ fact sheet.

3) Transfer file from disc onto system-5 minutes/ batch.

INFO-U FAXBACK started as a pilot project of the horticulture specialization in the metro toll-free calling area. With the positive response from the public, industry, and MES staff, it is envisioned that the system will grow to include all of M ES program areas. Collaboration among states will help reduce the staff time inputs for a quality system. M ES is interested in working with other extension services adopting fax-on-demand technology.

"The
horticulture
industry is
strongly
supportive of
INFO-U
FAXBACK as
a public
service"

